\title{
The effect of concrete creep on the long-term tension-stiffening law and prediction of a time-dependent inertia moment of the cracked RC flexural cross-sections
}

\author{
Robertas Balevičius \\ Department of Reinforced Concrete Structures and Geotechnics, Faculty of Civil Engineering, \\ Vilnius Gediminas Technical University, Vilnius, Lithuania \\ E-mail: robertas.balevicius@vgtu.lt
}

\begin{abstract}
In the paper, a long-term stress-strain model is proposed for predicting the deformational response of the cracked reinforced concrete beams subjected to sustained bending. The linear and non-linear evolution creep strains is evaluated in the analytical manner by using an average stress-strain approach. The cracking and creep phenomena are coupled by two reologic elements connected in a series. In this way, the total strain of concrete prior to cracking is determined by a linear creep law accounting for the stress rate effect, while the post-cracking behavior is specified as a sum of elastic strain between cracks, creep and cracked concrete strain, defined by the descending branch of the stress-strain law. The smeared crack approach is adopted and, in turn, this law is associated with the tension stiffening phenomenon. The formulae accounting for the tension stiffening decay with time due to time-variable stress are proposed and applied in prediction of the inertia moment of the cracked $\mathrm{RC}$ flexural members along with the obtained results verification with the experimental data.
\end{abstract}

Keywords: long-term tension stiffening, creep, coefficient of ageing, average stress strain approach, Volterra integral.

\section{Introduction}

The proper theoretical anticipation of concrete creep, shrinkage and cracking phenomena is very important in design of reinforced concrete (RC) structures. It is well established that the long-term tension stiffening, as the contribution of the concrete in tension between the cracks to the whole member stiffness, decays with time largely due to tensile creep under sustained loading (Gilbert \& Wu, 2009; Scott \& Beeby, 2005). However, the existing code-based approaches for evaluating this phenomenon are quite general and make no attempt to quantify a law of tension-stiffening decay with time. Via code formulations, the tension stiffening effect reduces to about a half its initial value, in the long-term. As far as can be ascertained, a very few techniques exist in theoretical prediction how tension stiffening changes as a function of time, especially, when the modeling concerns the time-dependent evaluation of stress history. It results in difficulties for calculating the development of the stiffnesses and deflections of RC members with time (Gilbert, 2013) and it is this issue addressed by the current work.

In the paper, the analytical approach for predicting the long-term stress-strain state of the cracked RC beams under sustained load is developed by combination of the average stress strain approach (Balevičius, 2010) for creep analysis with an effective stiffness model of cracked cross-sections (Balevičius, 2006). The formulae accounting for the tension stiffening decay with time due to time-variable stress are derived and applied in prediction of the inertia moment of the cracked RC flexural members along with the obtained results verification with the experimental data.

\section{Governing equilibrium equations and cross-section stiffness}

Consider a statically determined non-prestressed beam as a doubly reinforced concrete element subjected to sustained bending (Figure 1). Using the requirements of strain compatibility between concrete and reinforcement and denoting stresses and strains by subscripts $c / c t$ and $s / s 1$ for the compressive/tensile concrete and for the compressive/tensile reinforcements, the equilibrium equations at time $t$ can be written as follows: 


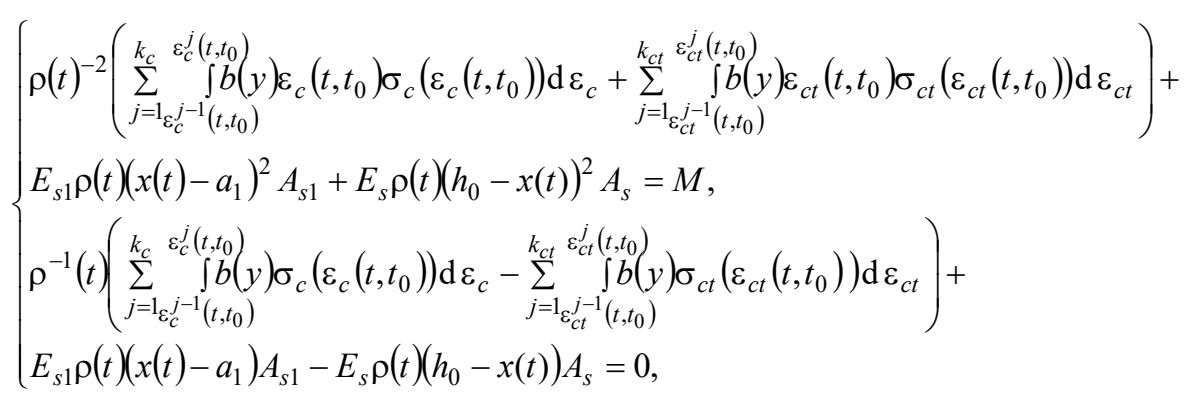

where: $M$ is the sustained external bending moment; $\varepsilon_{c}^{j-1}\left(t, t_{0}\right), \varepsilon_{c}^{j}\left(t, t_{0}\right), \varepsilon_{c t}^{j-1}\left(t, t_{0}\right), \varepsilon_{c t}^{j}\left(t, t_{0}\right)$ are the average strains of $t_{0}$-age concrete acting on $j$-th and $j$-1-th layers and developed at time $t$ (Figure 1); $\rho(t)$ is curvature at $t$; $x(t)$ is the position of the neutral axis at time $t$ of the transformed cross-section (Figure 1); $b(y)$ is the width of cross section at vertical distance $y$ (Figure 1); $h_{0}=h-a$ is the effective, while $h$ is the overall depths of the cross section; $a_{1}$ and $a$ are the distances between centre of gravity of compressive and tensile reinforcements to the nearest edges of the cross section; $A_{s 1}$ and $A_{s}$ are the area of reinforcements (Figure 1).

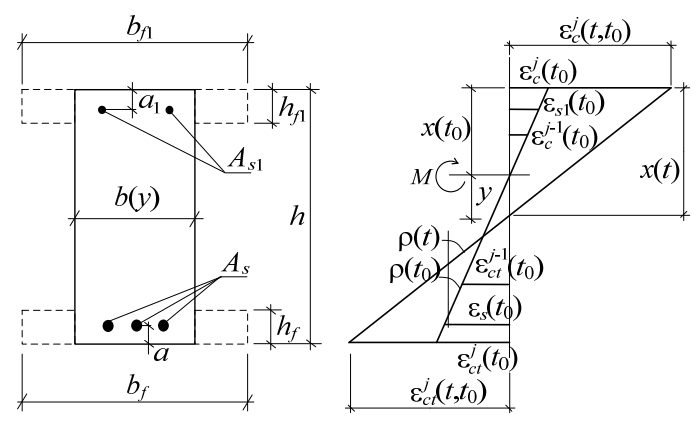

Figure 1. Development of strains within the cross-section

In general, the set of equilibrium equations is nonlinear and analytically irresolvable for the unknown curvature and neutral axis position of the cracked cross-sections even when $t=t_{0}$. The approximate solution is feasible, when the secant modulus-based stress-strain diagram is substituted for the nonlinear response of concrete under compression. Moreover, a separation of equations in the set (1), as a linearization of neutral axis function vs. internal bending moments, is required to obtain a third order polynomial (Balevičius, 2006). Thereby, this solution in terms of an effective moment of inertia (Balevičius, 2006), reflecting four stages of the tension zone behavior under cracking is implemented thereinafter along with the application of an analytical average stress and strain approach for evaluating the effect of creep (Balevičius, 2010). Hence, the solution of Eq. (1) is defined as

$$
\begin{gathered}
\rho(t)=\frac{M}{E_{c}(t) J^{e f f}(t)}, J^{e f f}(t)>0, J^{e f f}(t) \in \mathbf{R}, \\
x(t)=\left\{\begin{array}{l}
x_{p r, s t f}(t)+\left(x_{c r}(t)-x_{p r, s t f}(t)\right) \frac{M_{p r, s t f}-M}{M_{p r, s t f}-M_{c r}}, M_{c r} \leq M \leq M_{p r, s t f}, \\
x_{f, c r}(t)+\left(x_{p r, s t f}(t)-x_{f, c r}(t)\right) \frac{M_{u, l t}-M}{M_{u, l t}-M_{p r, s t f}}, M_{p r, s t f}<M \leq M_{u, l t},
\end{array}\right.
\end{gathered}
$$

where: $E_{c}(t)$ is the modulus of elasticity at $t ; J^{\text {eff }}(t)$ is the time-dependent effective moment of inertia of the cracked cross-section; $x_{c r}(t), x_{p r, s t f}(t), x_{f, c r}(t)$ are the positions of the neutral axis at $t$ due to sustained actions of the moment inducing first crack $M_{c r}$, the moment specifying the end of pure tension stiffening stage $M_{p r, s t f}$ and long-term ultimate moment of RC cross-section $M_{u, l t}$, respectively (Balevičius, 2006). 
The effective moment of inertia of the cracked cross-section for the case of sustained loading is patterned after (Balevičius, 2006):

$$
J^{e f f}(t)=\left\{\begin{array}{l}
J_{p r, s t f}^{e f f}(t), M_{c r}<M \leq M_{p r, s t f} \\
J_{p t, s t f}^{e f f}(t), M_{p r, s t f}<M \leq M_{u, l t}
\end{array}, \quad J^{e f f}(t) \in \mathbf{R}\right.
$$

where: $J_{p r, s t f}^{e f f} 1,2,3(t)=\frac{3 M J_{p r, s t f}(t)}{\Delta M_{p r, s t f}(t)\left(\operatorname{sign}\left(\Delta \rho_{p r, s t f}(t)\right) 2 \cos \left(\frac{1}{3} \varphi_{p r, s t f}(t)+z^{1,2,3}\right)-1\right)}$ is the effective moment of inertia in

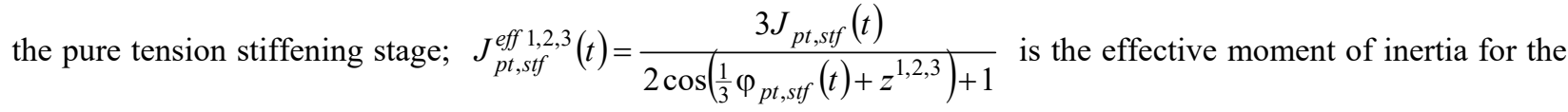
partial tension stiffening stage; $\Delta M_{p r, s t f}(t)=S_{p r, s t f}^{c t}(t) E_{c t}^{t g}(t) \beta(t) \varepsilon_{c t R}(t)-M$ and $\Delta \rho_{p r, s t f}(t)=\frac{\Delta M_{p r, s t f}(t)}{E_{c}(t) J_{p r, s t f}(t)}$ are the bending moment and curvature increments at time $t$ due to pure effect of tension stiffening; $z^{1,2,3}=\{0,2 \pi / 3,4 \pi / 3\} \quad$ specifies the constants for defining three roots of $J^{\text {eff }}(t)$; $J_{p r, s t f}(t)=J_{p r, s t f}^{c}(t)-J_{p r, s t f}^{c t}(t)+n_{c}(t) J_{p r, s t f}^{s}(t), \quad J_{p t, s t f}(t)=J_{p r, s t f}^{c}(t)+n_{c}(t) J_{p r, s t f}^{s}(t)$ are the transformed section inertia moments about $x(t)$ in the pure and partially tension stiffening stages; $J_{p r, s t f}^{c}(t)=v_{c}\left(t, t_{0}\right)\left(\omega \omega_{1} b x^{3}(t)+\left(b_{f 1}-b\right) h_{f 1}\left(x^{2}(t)-x(t) h_{f 1} /\left(2 \omega_{0}\right)+\omega_{1} \omega_{f 1} h_{f 1}^{2}\right)\right)$ is the inertia moments of the compressive and tensile concrete $\left.J_{p r, s t f}^{c t}(t)=\frac{1}{3} n_{c t}(t) b(h-x(t))^{3}+\frac{1}{3}\left(b_{f}-b\right) h_{f} n_{c t}(t)\left[(h-x(t))^{3}-\left(h-x(t)-h_{f}\right)^{3}\right] / h_{f}\right)$ zones; $\quad J_{p r, s t f}^{s}(t)=A_{s 1}\left(x(t)-a_{1}\right)^{2}+A_{s}(d-x(t))$ is the same for reinforcement $n_{c t}(t)=E_{c t}^{t g}(t) / E_{c}(t) \quad$; $n_{c}(t)=E_{s} / E_{c}(t) ; E_{c t}^{t g}(t)$ is the tangent modulus of the post-cracking (i.e., descending branch) stress-strain diagram at $t ; \quad S_{p r, s t f}^{c t}(t)=\frac{1}{2} b(h-x(t))^{2}+\left(b_{f}-b\right) h_{f}\left(h-x(t)-\frac{1}{2} h_{f}\right)$ is the first moment of tensile concrete area about $x(t)$ at $t ; \varepsilon_{c t R, \max }(t)=\beta(t) \varepsilon_{c t R}(t)$ is the limit average (via the smeared cracks meaning) strain of cracked concrete at time $t$ accounting for long-term tensioned stiffening; $\varepsilon_{c t R}(t)$ is the limit tensile strain of uncracked concrete at time $t$ accounting for the tensile stress rate developing in tensile zone of the beam; $\beta(t)$ is the factor defining the long-term limit cracking strain of concrete; $\omega, \omega_{1}, \omega_{0}, \omega_{f 1}$ are the compressive stress diagram shape parameters (Balevičius, 2006); $v_{c}\left(t, t_{0}\right)$ is the function defining secant modulus of elasticity subjected to a time-variable stress, creep and partially recoverable compressive strains of concrete.

The other parameters, evaluating the long term tension stiffening in the above equations are:

$$
\begin{gathered}
\cos \left(\varphi_{p r, s t f}(t)\right)=\frac{-9\left(v_{c t}\left(t, t_{0}\right)+3 n_{c t}(t)\left(\frac{1}{3}-\frac{1}{2} \beta(t)\right)\right) E_{c}^{3}\left(t_{0}\right) J_{p r, s t f}^{3}(t) \varepsilon_{c t R}^{3}(t) b}{\operatorname{sign}\left(\Delta \rho_{p r, s t f}^{3}(t)\right) 2 J_{p r, s t f}(t) \Delta M_{p r, s t f}^{3}(t)}-\operatorname{sign}\left(\Delta \rho_{p r, s t f}^{3}(t)\right) ; \\
\cos \left(\varphi_{p t, s t f}(t)\right)=1-\frac{9\left(v_{c t}\left(t, t_{0}\right)+n_{c t}(t)\left(\frac{1}{2} \beta(t)\left(\beta^{2}(t)-3\right)+1\right)\right) J_{p t, s t f}^{2}(t) E_{c}^{3}\left(t_{0}\right) \varepsilon_{c t R}^{3}(t) b}{2 M^{3}},
\end{gathered}
$$

where $v_{c t}\left(t, t_{0}\right)$ is the function defining secant modulus subjected to a time-variable stress, creep and partially recoverable tensile strains of concrete (given in below).

\section{A time-dependent constitutive modeling of concrete properties}

\section{Concrete under compression}

The time-dependent behavior of plain concrete is viewed as a visco-elastic-ageing material subjected to a gradual evolution of stress. The total strain of concrete in compression at any age $\tau$ is composed of four components:

$$
\varepsilon_{c}(t, \tau)=\varepsilon_{c}\left(t_{0}\right)+\varepsilon_{c, c r}^{l i n}(t, \tau)+\varepsilon_{c, c r}^{n l}(\eta(\tau), t, \tau)+\varepsilon_{s h r}\left(t, \tau^{\prime}\right)
$$

where $\varepsilon_{c}\left(t_{0}\right)$ is the short-term strain at age of loading $t_{0} ; \varepsilon_{c, c r}^{\operatorname{lin}}(t, \tau)$ is the linear creep strain at $t$ that increment is invariant of any previous stress and depends on the current stress rate $\mathrm{d} \sigma_{c}(\tau)$ at any age $\tau, \varepsilon_{c, c r}^{n l}(\eta(\tau), t, \tau)$ is the 
nonlinear creep strain pertained to the stress level $\eta(\tau)$ at any age $\tau, \varepsilon_{s h r}\left(t, \tau^{\prime}\right)$ is a stress-invariant strain of concrete shrinkage, which starts at the end of moist curing time $\tau^{\prime}$ and evolves with time $t$ (specified separately on the basis of the principle of superposition).

A short-term strain is defined via secant modulus concept, $E_{c}^{\mathrm{sec}}\left(t_{0}\right)=v E_{c}\left(t_{0}\right)$, where $v$ is the coefficient of elasto-plasticity in compression. Meanwhile, the linear and non-linear creep strains, induced by the stress rate $\dot{\sigma}_{c}$, are superimposed using Arutyunyan's (1966) nonlinear formulation in terms of a series Volterra's integral equations of the second kind. Thus, Eq. (7) is rewritten as:

$$
\varepsilon_{c}\left(t, t_{0}\right)=\underbrace{\frac{\sigma_{c}\left(t_{0}\right)}{v E_{c}\left(t_{0}\right)}+\int_{t_{0}}^{t} \frac{1}{v E_{c}(\tau)} \frac{\mathrm{d} \sigma_{c}(\tau)}{\mathrm{d} \tau} \mathrm{d} \tau}_{\varepsilon_{c}}+\underbrace{F\left[\sigma_{c}\left(t_{0}\right)\right] C\left(t, t_{0}\right)+\int_{t_{0}}^{t} \frac{\mathrm{d} F\left[\sigma_{c}(\tau)\right]}{\mathrm{d} \tau} C(t, \tau) \mathrm{d} \tau}_{\varepsilon_{c, c r}^{i n}+\varepsilon_{c, c r}^{n l}},
$$

where $\sigma_{c}(\tau)$ and $F\left[\sigma_{c}(\tau)\right]$ are the compressive stress of concrete and creep non-linearity function at current age $\tau$, respectively, $C(t, \tau)$ is the specific creep. braced:

An affinity between the nonlinear and linear creep strains is supposed and (NIIZHB, 1988) function is em-

$$
F\left[\sigma_{c}(\tau)\right]=\sigma_{c}(\tau)\left[1+\vartheta\left(\sigma_{c}(\tau) / f_{p r}(\tau)\right)^{n}\right], \quad \sigma_{c}\left(t_{0}\right)>0.5 f_{p r}\left(t_{0}\right),
$$

where: $\vartheta$ is the factor defining the increase in the nonlinear creep strain at the delayed failure, $f_{p r}$ stands for the mean strength value of concrete prism, $m=4$ is the exponent.

A partial integration of Eq. (8), application of the first mean theorem on integration and comparison with the secant modulus-based stress-strain law $\varepsilon_{c}\left(t, t_{0}\right)=\sigma_{c}(t) /\left(v_{c}\left(t, t_{0}\right) E_{c}(t)\right)$ we have:

$$
v_{c}\left(t, t_{0}\right)=\frac{1}{1 / v+H(\xi) E_{c}(t)\left(C_{v}^{*}\left(t, t_{0}\right)+\vartheta \eta(\xi)^{m} C\left(t, t_{0}\right)\right)}, \quad \xi \in\left[t, t_{0}\right]
$$

where: $H(\xi)=\sigma_{c}(\xi) / \sigma_{c}(t)$ is the stress relaxation index in $\left[t, t_{0}\right]$, resulted from the stress rate $\dot{\sigma}_{c}(\tau)$; $\eta(\xi)=\sigma_{c}(\xi) / f_{p r}(\xi)$ is the level of the average stress $\sigma_{c}(\xi)$ to the average strength $f_{p r}(\xi)$ both in the sense to fulfill Volterra's integral in $\left[t, t_{0}\right]$ (Balevičius 2010), $C_{v}^{*}\left(t, t_{0}\right)=\frac{1}{v E_{c}\left(t_{0}\right)}-\frac{1}{v E_{c}(t)}+C\left(t, t_{0}\right)$ is the pure specific creep evaluating the part of irrecoverable short-term plastic strain of compressive concrete.

In general, the average stress $\sigma_{c}(\xi)$ is provided for the roots of nonlinear equation of order $m+1$ :

$$
\left\{\sigma_{c}\left(\xi_{1}\right), \ldots, \sigma_{c}\left(\xi_{m+1}\right)\right\} \in\left\{\sigma_{c}(\xi) \mid f\left(\sigma_{c}(\xi)\right)=0\right\},
$$

where $f\left(\sigma_{c}(\xi)\right)=-\sigma_{c}(\xi) C_{v}^{*}\left(t, t_{0}\right)-\vartheta \sigma_{c}(\xi) \eta(\xi)^{m} C\left(t, t_{0}\right)-\int_{t_{0}}^{t} \sigma_{c}(\tau)\left(\mathrm{d} \delta(t, \tau)+\vartheta \eta(\tau)^{m} \mathrm{~d} C(t, \tau)\right)$, in which, the both integral are treated as Stieltjes integrals; $\delta(t, \tau)$ is the compliance of creep.

When the concrete stress is proportional to the creep strain, the stress relaxation index can be found using the average stress and strain approach (Balevičius 2010) from the equation defining the coefficient of ageing

$$
\chi\left(t, t_{0}\right)=\frac{\sigma_{c}(\xi)-\sigma_{c}\left(t_{0}\right)}{\sigma_{c}(t)-\sigma_{c}\left(t_{0}\right)}=\frac{\sigma_{c}(\xi)-\sigma_{c}\left(t_{0}\right)}{\Delta \sigma_{c}(t)}, \quad E_{c}(t)=E_{c}\left(t_{0}\right),
$$

which is clarified as a continuous shape function $\chi\left(t, t_{0}\right) \in[0,1]$ of concrete stress change $\Delta \sigma_{c}(t)$ (Balevičius \& Augonis, 2018). In this case, the problem for assessment of concrete stress history of the uncracked RC cross-sections exactly reduces to prediction of $\sigma_{c}(\xi)$ from the single quasi-elastic equation by substituting the age-adjusted effective modulus of elasticity for $E_{c}\left(t_{0}\right)$, if $\chi\left(t, t_{0}\right)$ is pre-defined (Balevičius, 2010).

\section{Concrete under tension}

The long-term evolution of tensile strains is dependent on tensile stress history evolving in the tensile zone of RC beam. Bažant and Chern (1985) proposed an approach for coupling the cracking and creep phenomena by adopting two reologic elements connected in a series. Thus, the total long-term strain of concrete prior to cracking can be determined by the linear creep law, and after cracking it expresses as a sum of elastic strain between cracks, creep 
and strain due to cracks, which is associated with the descending branch of the stress-strain law (Chern \& Marchertas, 1985). Generally, this concept is applied below, where the cracked concrete strain is specified by the monotonically descending stress-strain relationship and considered as the additive quantity to creep and elastic strains. So:

$$
\sigma_{c t}\left[\varepsilon_{c t}\left(t, t_{0}\right)\right]=\left\{\begin{array}{l}
\varepsilon_{c t}\left(t, t_{0}\right) v_{c t}\left(t, t_{0}\right) E_{c}\left(t_{0}\right), 0<\varepsilon_{c t}\left(t, t_{0}\right) \leq \varepsilon_{c t R}(t), \\
\alpha \sigma_{c t R}(t)-E_{c t}^{t g}(t)\left[\varepsilon_{c t}\left(t, t_{0}\right)-\varepsilon_{c t R}(t)\right], \varepsilon_{c t R}(t)<\varepsilon_{c t}\left(t, t_{0}\right)<\varepsilon_{c t R, \text { max }}(t),
\end{array}\right.
$$

where: $\alpha$ is the factor evaluating drop in the descending branch of the stress-strain branch $(\alpha=0.7$ could be selected, Balevičius, 2006); $\sigma_{c t R}(t)$ is the tensile stress of concrete developed at time $t$ in the extreme tensile fibre of RC cross-section due to $M=M_{c r}$ applied at $t_{0} ; \varepsilon_{c t}\left(t, t_{0}\right)$ is the total tensile strain at $t$ resulted from a time-variable stress $\sigma_{c t}(t)$.

Now, let us relate the parameters of stress-strain law (13) with concrete stress evolution in the tensile zone of $\mathrm{RC}$ beam. In this case, the stress-strain state should be related with the corresponding external moments and ascending (elastic and creep) and descending (cracked) stress-strain laws can be considered separately. Thereby, in the pre-cracking stage the elastic and creep strains are defined by adopting Eq. (10); thus:

$$
v_{c t}\left(t, t_{0}\right)=\frac{1}{1 / v_{c t}+H_{c t}(\xi) E_{c}(t) C_{v}^{*}\left(t, t_{0}\right)}, \quad \xi \in\left[t, t_{0}\right],
$$

where: $H_{c t}(\xi)=\sigma_{c t}(\xi) / \sigma_{c t R}(t)$ is the tensile stress relaxation index in $\left[t, t_{0}\right]$, resulted from the stress rate $\dot{\sigma}_{c t}(\tau)$ and calculated from second formula in Eq. (12); $\sigma_{c t}(\xi)$ is defined from solution of stress-strain state at $t$ induced by due to $M=M_{c r}$ for the transformed age-adjusted cross-section (Balevičius, 2010); $\sigma_{c t R}(t)=v_{c t}\left(t, t_{0}\right) E_{c}(t) \varepsilon_{c t R}(t)$; $\varepsilon_{c t R}(t)=M_{c r}\left[h-x_{c r}(t)\right] /\left(E_{c}(t) I_{c r}(t)\right)$ is the extreme tensile fibre strain of the cross-section defined using $x_{c r}(t)$ and $I_{c r}(t)$ by the formulae given in (Balevičius, Augonis, Kliukas, \& Bistrickaite, 2016) inserting $v_{c t}\left(t, t_{0}\right)$ and $v_{c}\left(t, t_{0}\right)$ instead of $v_{c t}$ and $v$, respectively.

When $\sigma_{c t R}(t)$ and $\varepsilon_{c t R}(t)$, defining the end of pre-cracking stage, are established, a prediction of the limit strain of cracked concrete $\varepsilon_{c t R \text {,max }}(t)$ provides essentially for the solution of the equilibrium equation, when no tensile stress is carried $\sigma_{c t}\left(\varepsilon_{c t R, \max }(t)\right)=0$ at the extreme tensile fibre of RC cross-section, if $M=M_{p r, s t f}$ is held constant. Hence, by applying the equilibrium of bending moments, the ratio $\beta(t)=\varepsilon_{c t R, \max }(t) / \varepsilon_{c t R}(t)$, controlling the tension stiffening degradation at $t$, can be resolved from the equation:

$$
f(\beta(t))=\beta(t)-\frac{M_{p r, s t f}\left(h-x_{p r, s t f}(t, \beta(t))\right)}{\varepsilon_{c t R}(t) E_{c}(t) I_{p r, s t f}(t, \beta(t))}=0,
$$

where: $x_{p r, s t f}(t, \beta(t))$ and $I_{p r, s t f}(t, \beta(t))$ is the neutral axis position and moment of inertia of the cracked cross-section at the end of pure tension stiffening stage as the functions of $\beta(t)$ given in (Balevičius et al., 2016) and should be predicted by inserting $v_{c t}\left(t, t_{0}\right)$ and $v_{c}\left(t, t_{0}\right)$ instead of $v_{c t}$ and $v$, respectively.

In general, Eq. (15) is nonlinear for $\beta(t)$ and there is no closed-form solution. Thereby, a two steps-based approximate solution is proposed. Firstly, we suppose that the limit tensile strain of cracked concrete be defined as the strain of a pure relaxation problem, i.e., $\varepsilon_{c t R, \max }(t)=\varepsilon_{c t R, \max }\left(t_{0}\right)=$ const, then we have

$$
\beta_{\text {relax }}(t)=\varepsilon_{\text {ctR, } \max }\left(t_{0}\right) / \varepsilon_{c t R}(t) \text {. }
$$

However, since the concrete strain at the tensile fibre builds-up with time due to creep, a gradual reduction of the resultant internal moment, i.e., $M_{p r, s t f}(t)<M_{p r, s t f}\left(t_{0}\right)=M$ occurs and equilibrium of bending moment is violated. Hence, in order to maintain sustained load, a gradual restore of the equilibrium to, $M_{p r, s t f}(t)=M_{p r, s t f}\left(t_{0}\right)=M$ is required, providing for $\varepsilon_{c t R, \max }(t)>\varepsilon_{c t R, \max }\left(t_{0}\right)$.

Thus, in the second step to restore the equilibrium and transit from $\beta_{\text {relax }}(t)$ to $\beta(t)$, the ratio $M_{p r, s t f}\left(t_{0}\right) / M_{p r, s t f}(t)$ is provided in Eq. (17), which finally gives the following formula.

$$
\beta(t)=\beta_{\text {relax }}(t) \frac{M_{p r, s t f}\left(t_{0}\right)}{M_{p r, s t f}(t)}=\beta\left(t_{0}\right) \frac{\varepsilon_{c t R}\left(t_{0}\right)}{\varepsilon_{c t R}(t)} \frac{I_{p r, s t f}\left(t_{0}\right)}{I_{p r, s t f}\left(t, \beta_{\text {relax }}(t)\right)} \frac{h-x_{p r, s t f}\left(t, \beta_{\text {relax }}(t)\right)}{h-x_{p r, s t f}\left(t_{0}\right)},
$$

where $\beta\left(t_{0}\right) \approx 5 \div 30$ (Bažant \& Oh, 1984; Kaklauskas \& Ghaboussi, 2001). 
Thus, the tension stiffening limiting function is dependent on the time-evolution of the ratio between the limit tensile strains of the uncracked concrete, the transformed inertia moments about the neutral axis $x_{p r, s t f}$ which accounts for the compressive and tensile stresses development via functions $v_{c t}\left(t, t_{0}\right), v_{c}\left(t, t_{0}\right)$. It also depends on the ratio of the tensile zone heights at time. In Prakhya and Morley (1990), the empirically described descending stress-strain curve was also related with the tensile zone height, area of reinforcement, etc.

In Figure 2, $\beta(t)$ is plotted for RC element subjected by a sustained bending moment $M=M_{p r, s t f}$ and low reinforcement ratio $\mu=0.35 \%$. The creep data is calculated by the code EC-2 (EN 1992-1-1, 2004). The numerical solution is performed by numerical procedures (Balevičius, 2010) for obtaining exact values of $\sigma_{c t}(\xi), \sigma_{c}(\xi)$ and $v_{c t}\left(t, t_{0}\right), v_{c}\left(t, t_{0}\right), \chi\left(t, t_{0}\right)$. Finally, using Eq. (15), the function $\beta(t)$ is resolved by adopting a Newton's step-based iterative procedure.

a)

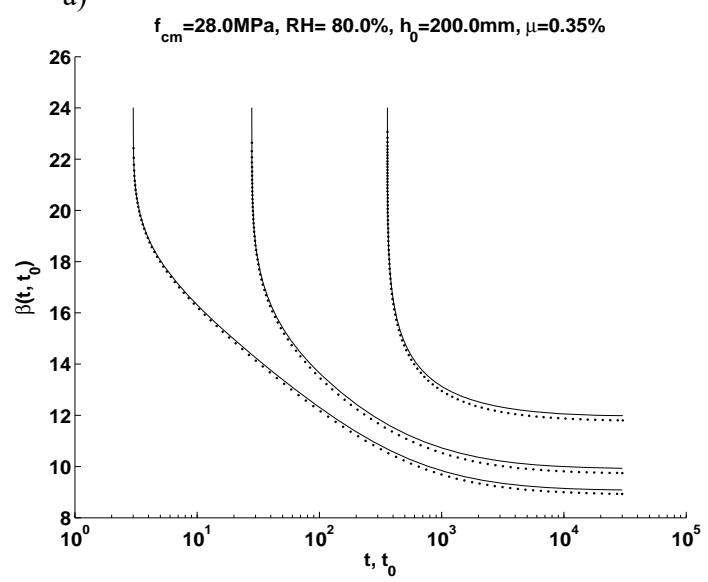

b)

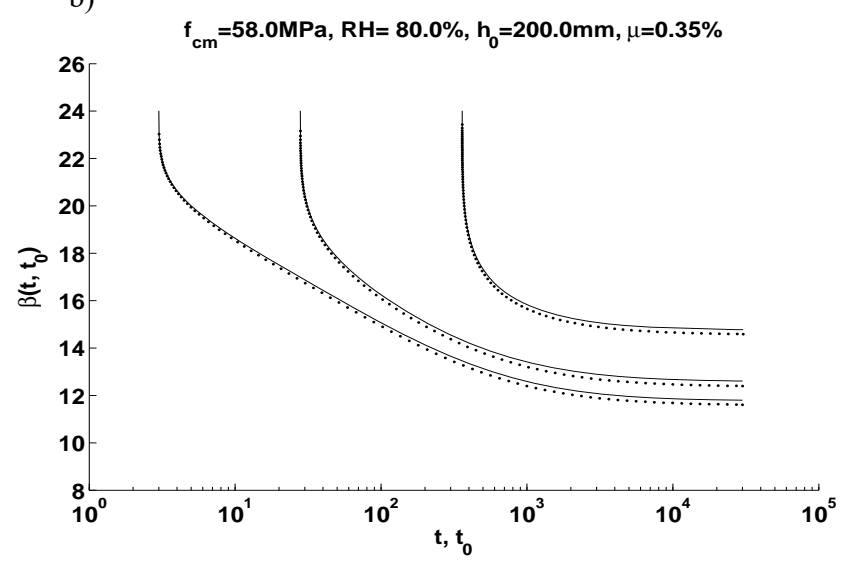

Figure 2. Time-evolution of tension stiffening limit function in the beam with low reinforcement ratio $\mu$ under sustained loading: a) low-strength concrete; b) high-strength concrete

As can be seen in Figure 2, the approximate Eq. (17) gives a sufficiently accurate (error $\pm 1-3 \%$ ) prediction vs. the numerical solution, and the ratio $M_{p r, s t f}\left(t_{0}\right) / M_{p r, s t f}(t)$ introduced is capable to restore the moments equilibrium, when the pure relaxation is considered first. Moreover, the descending evolution of $\beta(t)$ demonstrate a gradual degradation of tension stiffening with time. Particularly, a significant drop (by about $70 \%$ ) in tension stiffening occurs for element with small reinforcement ratio loaded at early age. For old concrete a decay of tension stiffening due to creep is smaller about $40 \%$, since the creep strains are greatly exhausted. Because the low strength concrete results in much higher creep strains, the reduction in tension stiffening is more rapid than for high strength concrete (cf., Figure $2 a$ and $b$ ).

\section{Analytical prediction of the time-dependent stress-strain state}

The analytical prediction of the stress-state at time $t$ combines the average stress strain approach for creep analysis (Balevičius, 2010) with an effective stiffness model (Balevičius, 2006). The analysis comprises three steps:

1) Prediction of a short-term stress-strain state at $t=t_{0}$ and specification of stress level to evaluate either linear or non-linear creep strans develops under sustained load;

2) Prediction of the stress-strain state at $t=\xi$ to assess stress history by specifying an average stresses $\sigma_{c}(\xi)$, $\sigma_{c t}(\xi), \beta(\xi)$, etc., using the age-adjusted modulus of elasticity. Note, for nonlinear creep, the stresses $\sigma_{c}(\xi)$, $\sigma_{c t}(\xi)$ are predicted aproximately as for the case of linear analysis.

3) Prediction of the stress-strain state at $t$ of the neutral axis of the cracked cross-section and effective moment of inertia of $J^{e f f}(t)$ and curvature $\rho(t)$, using $v_{c t}\left(t, t_{0}\right), v_{c}\left(t, t_{0}\right), \beta(t)$, etc.

\section{Comparison with the experimental data}

To compare the theoretical results with the experimental data the tests conducted by Hollington (1970) (double T shape cross-section beams), Oplachko (1970) (high load level $M / M_{u}$ ) and Figarovskyi (1962) (lightly reinforced beams) are selected (Figure 3). The shrinkage-induced deflections are predicted by the Eurocode (EC-2), and creep 
and shrinkage strain are also calculated by this code, if they were not given in the tests. The theoretical deflections were calculated by Maxwell-Mohr integral (Balevičius et al., 2016).

a)

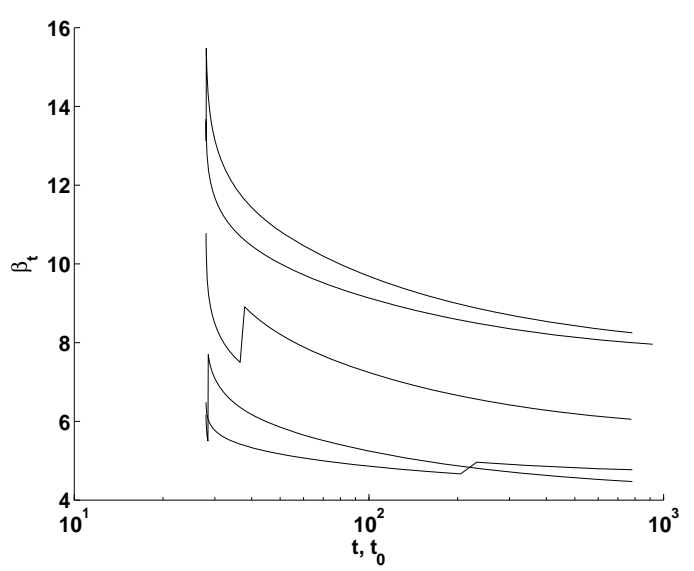

b)

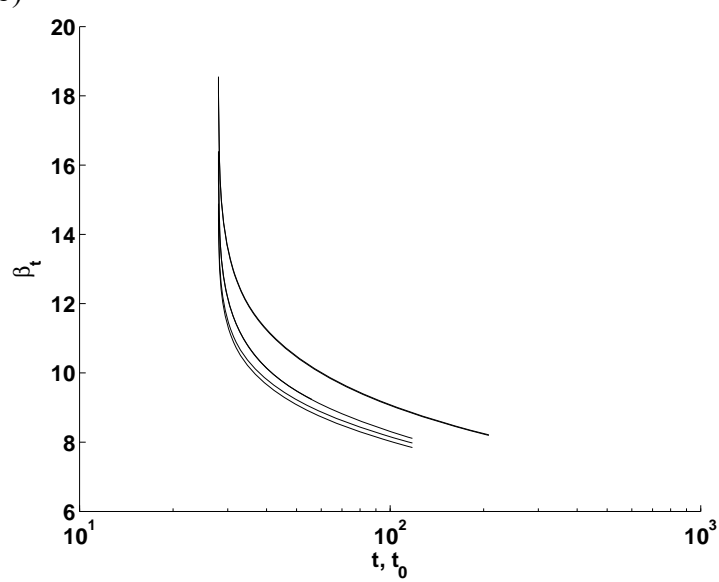

c)

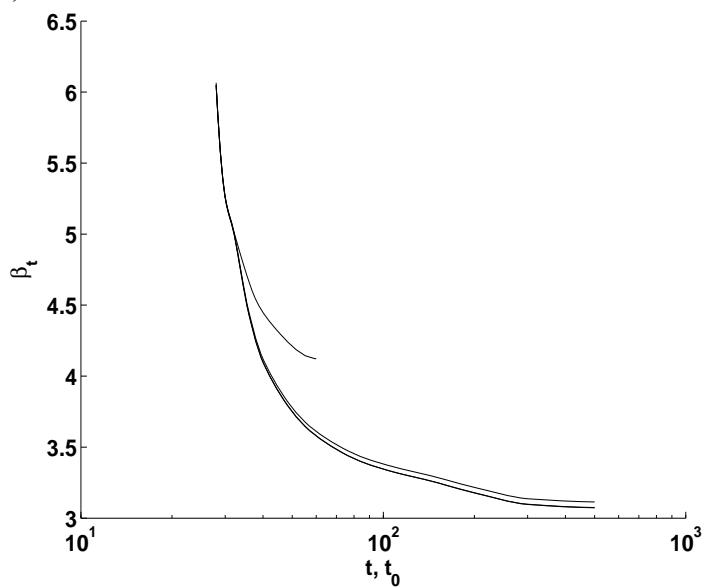

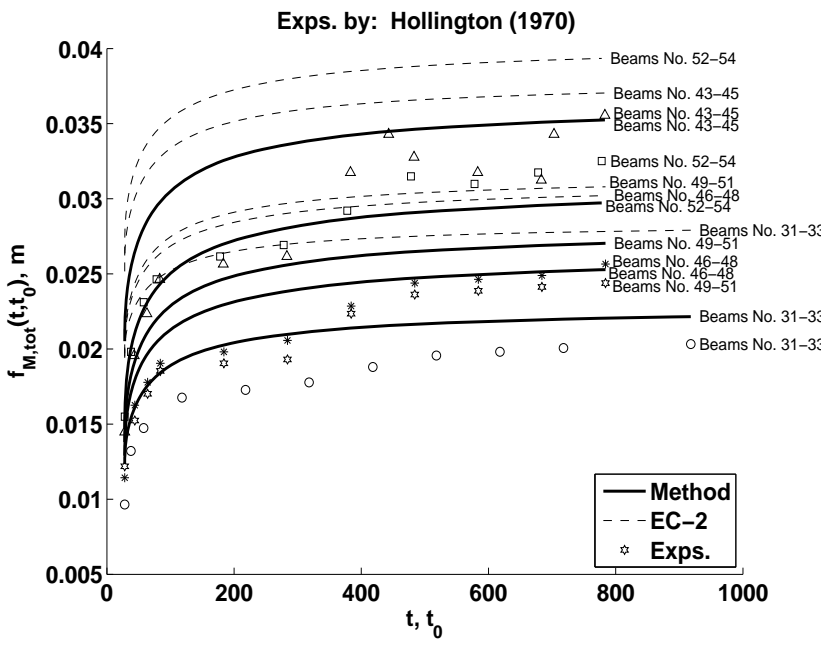

Exps. by: Figarovskyi (1962)

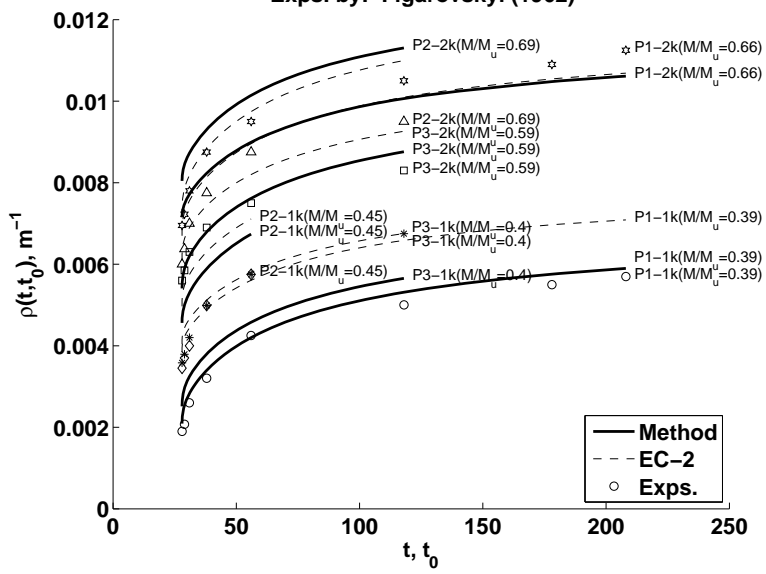

Exps. by: Oplachko (1970)

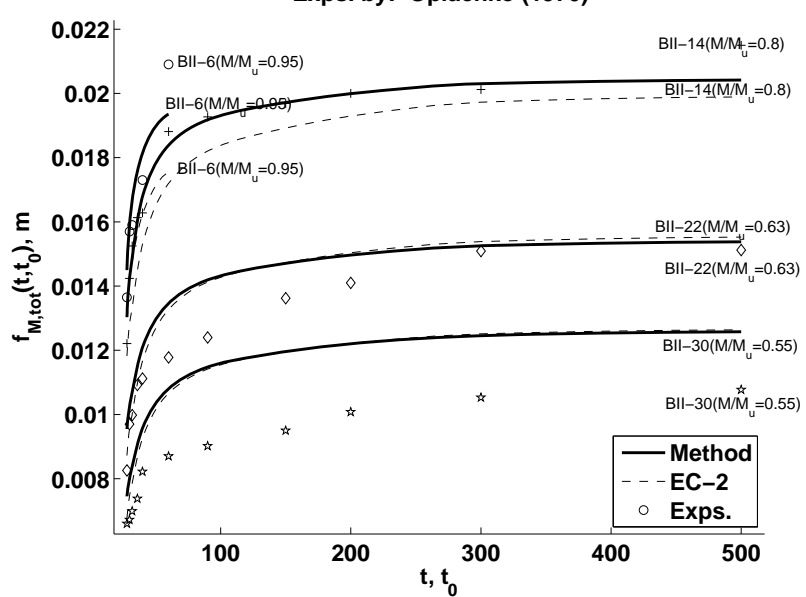

Figure 3. Graphs of the experimental and theoretical prediction of beam' deflections (curvatures) and tension stiffening function at $t$

As can be seen in Figure 3, the theoretical deflections match quite well the values obtained during long-term tests of cracked RC beams. The deflections resulted from the nonlinear creep and shrinkage strains are also in quite reasonable agreement with those measured in the experimental testing, when the high load levels were applied and kept until the delayed failure occurred (Figure 3c). Moreover, the agreement improves, when the creep and shrinkage data can be selected directly from the tests. The degradation of tension stiffening with time due to creep is more that twice in comparison with that occurring under short-term loading. The transition of the neutral axis from the com- 
pressive flange to the web of the cross-section results in the increase in the tension stiffening function (Figure 3a). The EC-2 based predictions are more conservative in comparison with those obtainable experimentally.

\section{Conclusions}

In the paper, the analytical approach for predicting the long-term stress-strain state of the cracked RC beams under sustained load has been proposed. It combines the average stress strain approach for creep analysis in order to evaluate the stress rate evolution with time along with an effective stiffness model to assess the cracking behavior and tension stiffening effect. The formulae accounting for the tension stiffening decay with time due to time-variable stress are also given and applied in prediction of the inertia moment of the cracked RC flexural members along with the obtained results verification with the experimental data.

A preliminary comparison of the theoretically calculated deflections with those obtained experimentally demonstrates quite accurate prediction. The degradation of tension stiffening with time is very sufficient and, in most cases, can be higher that twice from the initial value, depending on creep strains evoltion with time.

The enhanced comparative analysis is further required to evaluate the accuracy of the method.

\section{References}

Arutyunyan, N., Kh. (1966). Some problems in the theory of creep. Pergamon Press, Oxford.

Balevičius, R. (2006). An effective stiffness model for RC flexural members. Structural Engineering and Mechanics, 24(5), 601-620. https://doi.org/10.12989/sem.2006.24.5.601

Balevičius, R. (2010). An average stress strain approach to creep analysis of RC uncracked elements. Mechanics of Time-dependent Materials, 14, 69-89. https://doi.org/10.1007/s11043-009-9093-x

Balevičius, R., \& Augonis, M. (2018). The effects of bond, shrinkage and creep on cracking resistance of steel and GFRP RC members. Composite Structures, 187, 85-101. https://doi.org/10.1016/j.compstruct.2017.12.025

Balevičius, R., Augonis, M., Kliukas, R., \& Bistrickaite, R. (2016). An effective stiffness model for GFRP RC cracked flexural members. Composites Part B, 98, 415-433. https://doi.org/10.1016/j.compositesb.2016.05.050

Bažant, Z. P., \& Chern, J.-C. (1985). Strain softening with creep and exponential algorithm. Journal of Engineering Mechanics ASCE, 111(3), 391-415. https://doi.org/10.1061/(ASCE)0733-9399(1985)111:3(391)

Bažant, Z. P., \& Oh, B.-H. (1984). Deformation of progressively cracking reinforced concrete beams. ACI Structural Journal, 81(3), 268-278. https://doi.org/10.14359/10683

Chern, J. C., \& Marchertas, A. H. (1985). Long-term analysis of concrete structures with cracking. In Proceedings of the $8^{\text {th }}$ International Conference on Structural Mechanics in Reactor Technology. Paper 2/6. Brussels, Belgium.

European Committee for Standardization. (2004). Eurocode 2: Design of concrete structures. General rules and rules for buildings (EN 1992-1-1). CEN, Brussels.

Figarovskyi, V. V. (1962). Increase in the deflections of reinforced concrete beams subjected to long-term loading. Beton $i$ Zhelezobeton, 11, 501-503 (in Russian).

Gilbert, R. I. (2013). Time-dependent stiffness of cracked reinforced and composite concrete slabs. Procedia Engineering, 57, 19-34. https://doi.org/10.1016/j.proeng.2013.04.006

Gilbert, R. I., \& Wu, H. Q. (2009). Time-dependent stiffness of cracked reinforced concrete elements under sustained actions. Australian Journal of Structural Engineering, 9(2), 151-158. https://doi.org/10.1080/13287982.2009.11465018

Hollington, M. R. (1970). A series of long-term tests to investigate the deflection of a representative precast concrete floor component. C.C.A. (Technical report, TRA 442). London.

Kaklauskas, G., \& Ghaboussi, J. (2001). Stress-strain relations for cracked tensile concrete from RC beam tests. Journal of Engineering Mechanics ASCE, 127(1), 64-73. https://doi.org/10.1061/(ASCE)0733-9445(2001)127:1(64)

Concrete and Reinforced Concrete Research and Technological Institute (NIIZHB). (1988). Specifications for evaluation of concrete creep and shrinkage in the analysis of concrete and reinforced concrete structures. Moscow: Gosstroy (in Russian).

Oplachko, V. M. (1970). Long-term stress-strain state of reinforced concrete beams subjected to high level loads. In Long-term deformational processes in reinforced concrete structures (pp. 236-242). Moscow: Gosstroi (in Russian).

Prakhya, G. K. V., \& Morley, C. T. (1990). Tension stiffening and moment-curvature relations for reinforced concrete elements. ACI Structural Journal, 87(5), 597-605. https://doi.org/10.14359/2680

Scott, R. H., \& Beeby, A. W. (2005). Long-term tension stiffening effects in concrete. ACI Structural Journal, 102(1), 31-39. https://doi.org/10.14359/13528 